\title{
Supporting Transformative Agency among Urban Actors in the Change Laboratory Intervention
}

\author{
Virpi Lund ${ }^{1,2}$ \\ ${ }^{1}$ Laurea University of Applied Sciences, Espoo, Finland \\ ${ }^{2}$ Center for Research on Activity, Development and Learning, Faculty of Education, University of Helsinki, Helsinki, Finland \\ Email:virpi.lund@laurea.fi
}

How to cite this paper: Lund, V. (2021). Supporting Transformative Agency among Urban Actors in the Change Laboratory Intervention. Current Urban Studies, 9, 403418.

https://doi.org/10.4236/cus.2021.93025

Received: July 10, 2021

Accepted: August 6, 2021

Published: August 9, 2021

Copyright ( 2021 by author(s) and Scientific Research Publishing Inc. This work is licensed under the Creative Commons Attribution International License (CC BY 4.0).

http://creativecommons.org/licenses/by/4.0/ (c) (i) Open Access

\begin{abstract}
This paper contributes to the study of residents' and civil servants' transformative agency in urban development with the aid of the framework of cultural-historical activity theory. The aim is to investigate the emergence of transformative agency in five workshops, based on the method of Change Laboratory ${ }^{\oplus}$, in the city of Espoo, Finland. The formative intervention focused on exploring the collaboration of residents and actors in urban development. The workshop discussions were analysed with the help of the manifestations of contradictions in neighbourhood development connected to the expression of the types of transformative agency and elements of the human activity system. This enabled the identification of the topics of the discussions and the development of transformative agency through envisioning the developmental potential of the activity and taking action to transform it. The findings call attention to creating the tools and means to facilitate the participation and building the transformative agency through time.
\end{abstract}

\section{Keywords}

Activity Theory, Change Laboratory, Collaboration, Transformative Agency, Urban Development

\section{Introduction}

Transformative agency and the method of Change Laboratory ${ }^{\circledR}$ have been widely applied in studies on learning and change in work organizations but not explicitly in urban development. Transformative agency means "breaking away from the given frame of action and taking the initiative to transform it" (Virkkunen, 
2006: p. 49). It is a capacity to form and implement intensions that go beyond the accepted routines and given conditions of an activity and transform them (Engeström \& Sannino, 2013). Transformative agency emerges when people are confronted with concrete problematic situations, and it is analysed through the manifestations of the expressions of transformative agency (Engeström, 2011; Haapasaari, Engeström, \& Kerosuo, 2016; Sannino, 2008; Vänninen, Pereira-Querol, \& Engeström, 2015). The method of Change Laboratory is a formative intervention that generates transformative agency (Engeström, 2007, 2015; Virkkunen \& Newnham, 2013) through identifying and solving the contradictions embedded in the elements of the activity system.

The study builds on the setting of heterogeneous civil society and hierarchical cross-sectorial municipal administration in multi-actor urban development. The focus is on analysing the collaboration of residents and civil servants and the emergence of their transformative agency with the aid of the framework of cultural-historical activity theory (CHAT) (Vygotsky, 1978; Leont'ev, 1978). CHAT is a theory that operationalizes conceptual tools for data analysis to reveal the structural elements and motives behind the activities and their change over time. The manifestations of transformative agency occur in interaction with other people by taking the initiative to change practices by examining problems and envisioning new possibilities for the problems identified (see Haapasaari et al., 2016). The study contributes to enhancing the active role of residents and urban communities (Arnstein, 1969; Forester, 1982; Healey, 1992; Karaminejad, 2021) in the concrete collective processes of learning and development of transformative agency in response to the criticism of the effects of collaborative and participatory governance and practices (see Sandercock, 1998; Steen, Brandsen, \& Verschuere, 2018).

This study is a part of a three-year participatory action research project called "Caring and Sharing Networks", aimed at increasing residents' participation and enhancing efficient means for residents' and stakeholders' collaboration in urban development in the city of Espoo, Finland

(https://www.laurea.fi/hankkeet/v/valittavat-valittavat-verkostot/). The focus area is a part of the municipal district called Espoo Centre, with about 17,000 inhabitants. The lack of systematic stakeholder collaboration and residents' low engagement in development endeavours are challenges in the area. However, there is a strong will among stakeholders to enhance residents' participation and agency (Lund \& Juujärvi, 2018) and to exploit their resources in the neighbourhood development to act collectively for change in the area (Lund \& Kerosuo, 2019). The intervention in this study is motivated by the will of the civil society to participate in the decision-making processes and the administrative need to enhance collaboration between residents and civil servants in the city. A formative intervention was needed to tackle the existing challenges between the residents' and the public sector's needs, and as a start of the development of their transformative agency. The research question is: how does transformative agency emerge in 
the Change Laboratory intervention?

The paper is organized as follows. First the theoretical framework and the methodology of the study are presented. The findings are reported in terms of the emergence of expressions of transformative agency and the discussion topics of the transformative agency. Finally, the findings are discussed, and the conclusions are presented.

\section{The Activity-Theoretical Framework of the Study}

The theoretical framework of the study is based on CHAT, which provides a methodology to study transformative agency. The main concepts relevant to this study are transformative agency, the method of Change Laboratory, and activity system, which is presented as an analytical tool in Chapter 3.3.

Transformative agency operationalizes people's actions when they express and transform the object of their activity and build the ground for their collective action. The development of transformative agency enables people to achieve a joint activity and become masters of their actions by collectively explicating and envisioning new possibilities toward a joint object (Engeström, Sannino, \& Virkkunen, 2014). The emergence of transformative agency requires the process of expansive learning, which supports the qualitative transformations of collective human activity (Engeström, 2015, 2016). The principle of double stimulation is essential for building agency and intentionally affecting behaviour (Engeström, 2009; Sannino, 2015). It can be described as a conflict of motives, where a demanding problematic situation itself (first stimulus) starts the collective process of unveiling the contradiction. A mediating second stimulus (artefact) re-organizes and solves the contradiction in a goal-oriented way (Sannino, 2015). Transformative agency emerges in a situation that allows people to analyse, envision and redesign their activity collaboratively with the help of mediating tools (Haapasaari et al., 2016).

The method of Change Laboratory forms a comprehensive conceptual framework and effective tool for analysing and solving multidimensional problems collectively. As a formative intervention, it provides a place for participants' intensive collaboration on the developmental challenges of the activity, and for the dialectical relationship between individually manifested needs and the collectively elaborated joint object of the activity. It transforms the activity and builds up the participants' motivation based on a new understanding of the activity and a new perspective of its future development (Virkkunen \& Newnham, 2013). A setting of the Change Laboratory consists of a set of surfaces divided horizontally into three columns and vertically into three rows for presenting, reflecting, modelling and processing ideas temporally with intermediate cognitive tools. The participants are positioned as a group facing the surfaces, with the research tools such as videos, cameras, computers next to them and assistants and researcher-interventionists alongside (Engeström, Virkkunen, Helle, Pihlaja, \& Poikela, 1996). In Figure 1, the instruments of the Change Laboratory space are presented. 


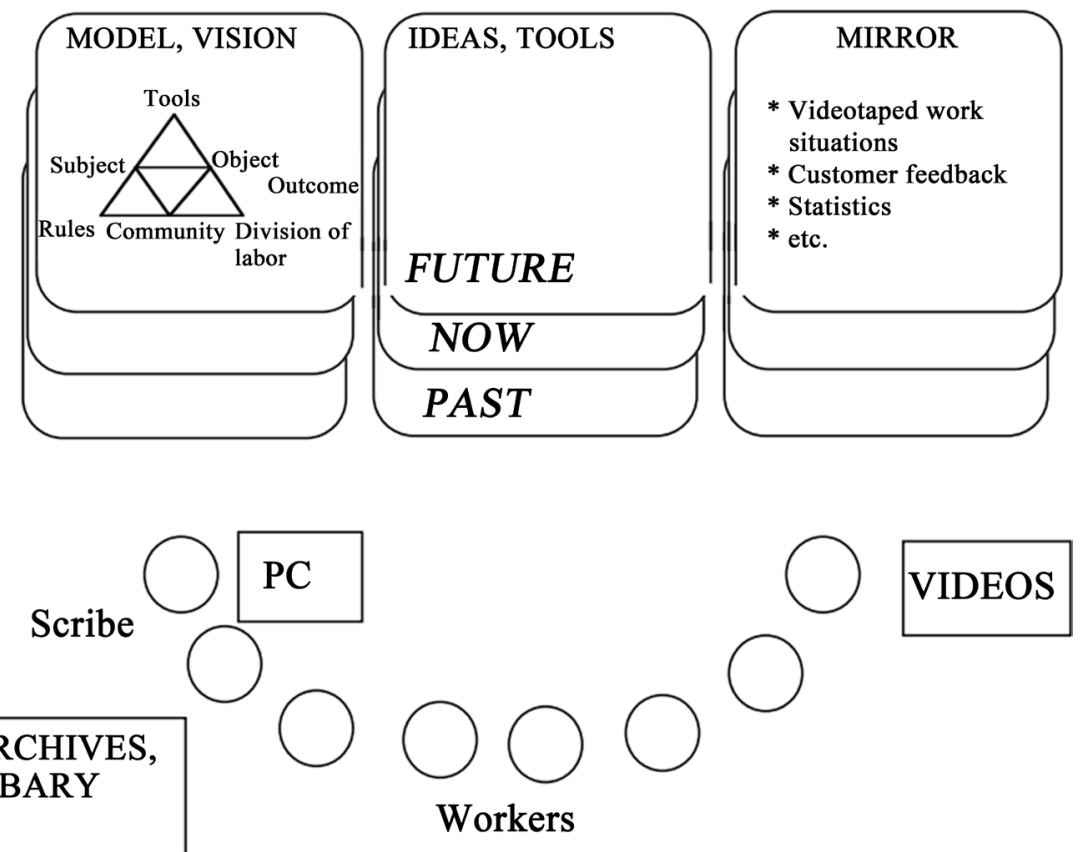

Figure 1. Layout of the Change Laboratory (adopted from Engeström et al., 1996: p. 11).

\section{Methodology}

\subsection{Context of the Study}

Espoo is the second-largest city in Finland, with almost 300,000 inhabitants. The focus area, Espoo Centre, is characterized by different historical layers in terms of construction, concentration of social housing, and waves of immigration from the 1970s onwards. In terms of socioeconomic indicators, it represents the most disadvantaged area in the city. The proportion of unemployed and uneducated people, single-parent and large families, and people on social welfare is high (City of Espoo, 2013; Hirvonen, 2011; Lehtinen, 2016). The area has a lively network of community associations that are mostly non-governmental organizations (https://www.espoo.fi/en-US/City of Espoo/Information about Espoo/Internat ional Espoo/Immigrant Services/Free time activities). Local associations, such as support for mental health (Emy), protect and help for abstinence (Askel), advisory service for immigrants (Trapesa), support for home economics (Martha Organization), and a great number of volunteers contribute to the community by helping people stay in charge of their own lives (also active members of this study). They help to prevent social exclusion by providing participatory activities, community building, and wellbeing for residents. They support participatory approaches that recognize the place-based local knowledge and expertise of residents.

The aims of the recent urban planning and development projects have been to promote the wellbeing of residents and to improve the communication between residents and public administration. The urban planning has been triggered by a need for more participatory tools to engage residents to influence their neighborhood issues. In line with the democratic principles of inclusiveness, citizens 
in Finland have a right to a say and local councils must ensure the diverse and effective opportunities for their participation in local government (Local Government Act, 2015). These include opportunities to participate in planning the municipality's finances, co-develop municipal services, and propose initiatives, as well as to traditional public discussions and hearings.

\subsection{Workshop Process and Participants}

The process of workshops was organized according the method of Change Laboratory to explore the systemic structure of the activities in the city and to achieve a holistic perspective for the long-term development of the activities (Virkkunen \& Newnham, 2013). The objective of the intervention was to facilitate the mapping of the future developmental needs of the neighbourhood and the collaboration of cross-sectorial municipality and civil society. Five successive workshops took place in Spring 2015 with an experimental implementation period of two months between the fourth and fifth workshop. Participants in workshops consisted of residents and members of residents' associations (18), representatives of non-governmental associations, local parishes, shopping malls and entrepreneurs (16), managers of regeneration projects, city planners, civil servants and experts in the city administration (10), and representatives of universities, research institutions, local schools and students (10). The ethnographic data produced by the residents during the earlier phases of the research project were utilized at the beginning of the preparation of the workshop process with researchers and crosssectorial civil servants. Table 1 describes the workshop process with their respective purposes and contents. The number of participants varied from 26 to 38 in workshops, resulting in 49 individuals. Some of them played two roles, for example being a resident and an expert in the city at the same time. During the workshop process the participants were divided in small groups which composed of different individuals each time.

According to the principle of double stimulation, the aim of the ethnographic mirror data as the first stimulus was to identify the problems in the neighbourhood and stimulate the collective analysis. The mirror data was comprised of the models of the future community centre (from civil servants' and residents' recent

Table 1. The process of the workshops.

\begin{tabular}{|c|c|c|c|c|}
\hline $\begin{array}{l}\text { 1. Workshop, } \\
34 \text { participants }\end{array}$ & $\begin{array}{l}\text { 2. Workshop, } \\
31 \text { participants }\end{array}$ & $\begin{array}{l}\text { 3. Workshop, } \\
38 \text { participants }\end{array}$ & $\begin{array}{l}\text { 4. Workshop, } \\
29 \text { participants }\end{array}$ & $\begin{array}{l}\text { 5. Workshop, } \\
26 \text { participants }\end{array}$ \\
\hline $\begin{array}{l}\text { Introducing the process of } \\
\text { the workshops and the } \\
\text { participants, exploring the } \\
\text { collective ways of working, } \\
\text { naming the current issues } \\
\text { in the neighbourhood. }\end{array}$ & $\begin{array}{l}\text { Presenting the concepts and } \\
\text { tools of the Change Laboratory } \\
\text { method and the mirror data } \\
\text { (first stimulus), analysing the } \\
\text { past disturbances, present } \\
\text { challenges, and future scenarios } \\
\text { of the neighbourhood with the } \\
\text { help of activity system model } \\
\text { (second stimulus). }\end{array}$ & $\begin{array}{l}\text { Explicating and } \\
\text { envisioning the } \\
\text { development of the } \\
\text { neighbourhood, selecting } \\
\text { the preliminary proposals } \\
\text { for further elaboration. }\end{array}$ & $\begin{array}{l}\text { Modelling the new forms of } \\
\text { activity, planning the } \\
\text { implementation actions for } \\
\text { the experimentation period } \\
\text { with the help of the checklist } \\
\text { of the practical details, aims, } \\
\text { subjects, timetable, follow-up } \\
\text { tool, result measurement tool, } \\
\text { activity system model. }\end{array}$ & $\begin{array}{l}\text { Presenting and evaluating } \\
\text { the experiments, defining } \\
\text { the future developmental } \\
\text { steps and agreeing upon } \\
\text { the follow-up. }\end{array}$ \\
\hline
\end{tabular}


interviews), a resident's experience of influencing the construction of the local school (from a resident's recent interview), the renewal of the rental agreement of an art gallery (from a tension-laden article in a local newspaper), and a resident's experience of the safety walk in the neighbourhood (from a resident's recent interview). The model of human activity system and disturbance matrix were used as mediating conceptual tools (second stimulus) to facilitate the problemsolving stimulated by mirror data. Some additional tools were used to organize the groups and their collaboration.

\subsection{Data and the Methods of the Study}

In this study, the process of the emergence of the transformative agency was followed by identifying the types of expressions of transformative agency and the elements of the model of the activity system related to speaking topics. This triggered the participants to follow the process of the transformation of the joint object and the other elements of the activity system related to the contradictions in the development of the neighbourhood (Engeström \& Sannino, 2010). A stepwise analysis of the discursive manifestations of the inner contradictions embedded in the elements of the model of activity system and expansive learning actions is reported elsewhere.

The data consists of group discussions from five video- and audio-recorded workshop sessions yielding 22 hours of recordings and 314 transcribed text pages in $8 \mathrm{pt}$ Verdana, single spacing, right and left margins $2 \mathrm{~cm}$, top and bottom margins $2.5 \mathrm{~cm}$. The development of the empirical analysis started with the author listening to the recordings several times and reading the transcribed data. The data were conducted carefully. As analytical tools, a speaking turn, a topic, and a topical episode were used in different phases of the analysis.

As the first step, the discourse data were divided into agentive and non-agentive speaking turns by roughly identifying the types of expressions of transformative agency and their emergence. Sometimes a speaking turn contained more than one type. The agentive speaking turns were analysed into actions by categorizing them according to the six types of expressions of transformative agency: resisting, criticizing, explicating, envisioning, committing to actions and reporting to have taken actions (Engeström, 2011; Haapasaari et al., 2016; Sannino, 2008; Vänninen et al., 2015), which are presented in Table 2 with examples of the manifestations.

As the second step, the topical contents of the discussions were explored in each session by classifying them according to the six elements of the activity system, namely subject, object, tools, rules, community and division of labour (Engeström, 2015), which are presented in Figure 2. In this vein, the results were kept in a coherent and understandable form by highlighting the topical contents. During the analysis, an extra topic had to be nominated, namely "participation", meaning that someone just explicates that she/he is interested in participating and being present during the implementation of the experiment without doing 
Table 2. The six types of expressions of transformative agency with their excerpts.

\begin{tabular}{|c|c|c|}
\hline Type of expression & Description & Excerpt \\
\hline Resisting & $\begin{array}{l}\text { Resisting the interventionist, management or change, } \\
\text { questioning, opposition, or rejection. }\end{array}$ & - \\
\hline Criticizing & Criticizing the current activity or organization. & $\begin{array}{l}\text { "I think that the current practices do not work. The main } \\
\text { question is what goes wrong in the public way of } \\
\text { operating?" }\end{array}$ \\
\hline Explicating & $\begin{array}{l}\text { Explicating new possibilities or potentials in the activity, relating } \\
\text { to past positive experiences, characterizing the problematic object } \\
\text { as a source of new possibilities. }\end{array}$ & $\begin{array}{l}\text { "The atmosphere in the development group is positive. } \\
\text { The discussions with cross-sectorial civil servants } \\
\text { concern practical concrete issues. Everyone is engaged } \\
\text { with the decisions." }\end{array}$ \\
\hline Envisioning & $\begin{array}{l}\text { Envisioning new patterns or models from partial preliminary } \\
\text { suggestions for the presentation and examination of } \\
\text { comprehensive models for the future. }\end{array}$ & $\begin{array}{l}\text { "It is utmost important that all the community } \\
\text { associations will be invited to the next planning sessions." }\end{array}$ \\
\hline $\begin{array}{l}\text { Committing to } \\
\text { actions }\end{array}$ & $\begin{array}{l}\text { Committing the concrete actions aimed at changing the activity } \\
\text { with commissive speech acts. }\end{array}$ & $\begin{array}{l}\text { "I have promised to take the main responsibility. I will } \\
\text { write the proposal on the form and send it." }\end{array}$ \\
\hline Taking actions & Taking consequential actions to change the activity. & "I have advertised the event in webpages." \\
\hline
\end{tabular}

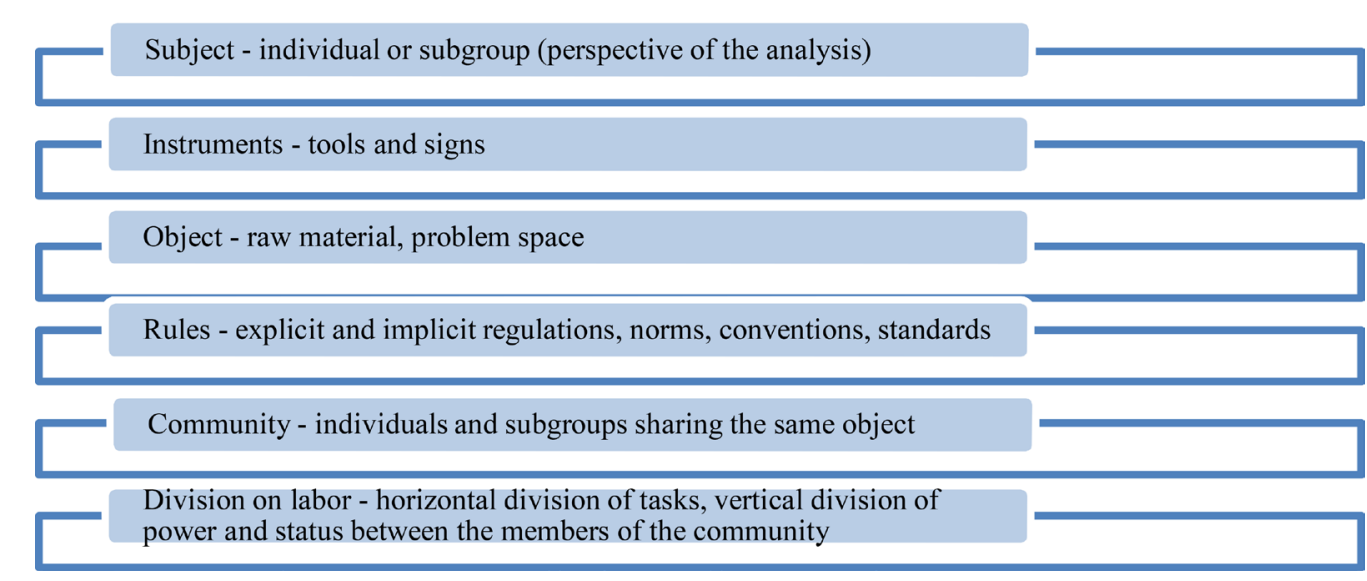

Figure 2. The six elements of an activity system (modified from Engeström, 2015).

anything. The following of the tensions between the official manifestations of the future visions of neighbourhood and the needs of the residents shed light on the agency building of the participants during the workshop process.

\section{Results}

The research question "how does transformative agency emerge in the Change Laboratory intervention" required the identification of the expressions of transformative agency in the speaking turns over the course of the workshop process. The emergence and evolution of the types of the expressions of transformative agency is followed in the sections below.

\subsection{The Emergence of the Types of Expressions of Transformative Agency}

Altogether, the transcribed data contained a total of 8556 speaking turns with 862 
agentive speaking turns containing expressions of transformative agency and 7694 non-agentive speaking turns. The non-agentive speaking turns were expressions of chatting together off-topic, negotiating how to draw figures or to locate information in the models, matrix or flip chart, and memorizing events in the area, names or addresses of the contact persons. A rather large number of non-agentive speaking turns (7694) may be due to the reason that the gatherings of residents were rare and thus included a lot of other social communication that originated from voluntary work and leisure activities. It may also indicate that the networks which seldom meet need to warm up their relations, and it is difficult to focus their talk directly on complex urban issues connected to different levels. Table 3 presents the frequencies of the types of the expressions of transformative agency in workshops.

There were in total 862 expressions of transformative agency in the course of the workshop process. The most frequent types of expressions of transformative agency were criticizing and explicating the new possibilities or potentials in the activity, which were both manifested 240 times. The expression of envisioning new patterns or models for the activity and organization was manifested a little less, altogether 236 times. The number of the expressions of committing to concrete actions to change the activity yielded 114 turns, and there were 32 expressions of reporting having taken the consequential actions to change the activity. The absence of the expressions of resisting may be due to both the civil servants and residents being ready for collaboration: they had been waiting for a chance to change the prevailing situation. The previous context-mapping interviews and residents' workshops in the research project in the mentioned area may have paved the way for the current will for the transformation process (Lund \& Juujärvi, 2018; Lund \& Kerosuo, 2019).

The evolution of the types of expressions of transformative agency in the workshop process is described in Figure 3. It shows two peaks in the frequency of agentive expressions, namely criticizing and committing to actions. Criticizing has its highest frequency (154) in the second workshop, which was expected since

Table 3. Expressions of the types of transformative agency and their frequency in five workshops.

\begin{tabular}{|c|c|c|c|c|c|c|c|c|c|}
\hline Work shop & Resisting & Criticizing & Explicating & Envisioning & Committing & $\begin{array}{l}\text { Taking } \\
\text { actions }\end{array}$ & $\begin{array}{l}\text { Non-agentive } \\
\text { turns }\end{array}$ & $\begin{array}{l}\text { Agentive } \\
\text { turns }\end{array}$ & $\begin{array}{l}\text { Total } \\
\text { turns }\end{array}$ \\
\hline 1 & 0 & 45 & 82 & 64 & 0 & 1 & 884 & 192 & 1076 \\
\hline 2 & 0 & 154 & 74 & 39 & 0 & 1 & 2554 & 268 & 2822 \\
\hline 3 & 0 & 21 & 46 & 47 & 3 & 0 & 1160 & 117 & 1277 \\
\hline 4 & 0 & 5 & 5 & 58 & 96 & 2 & 2223 & 166 & 2389 \\
\hline 5 & 0 & 15 & 33 & 28 & 15 & 28 & 873 & 119 & 992 \\
\hline Total & 0 & 240 & 240 & 236 & 114 & 32 & 7694 & 862 & 8556 \\
\hline$\%$ of all turns & 0 & 2.8 & 2.8 & 2.7 & 1.3 & 0.3 & & 9.9 & \\
\hline$\%$ of agentive turns & 0 & 27.8 & 27.8 & 27.4 & 13.2 & 3.7 & & 100 & \\
\hline
\end{tabular}


TYPE OF EXPRESSION OF TRANSFORMATIVE AGENCY

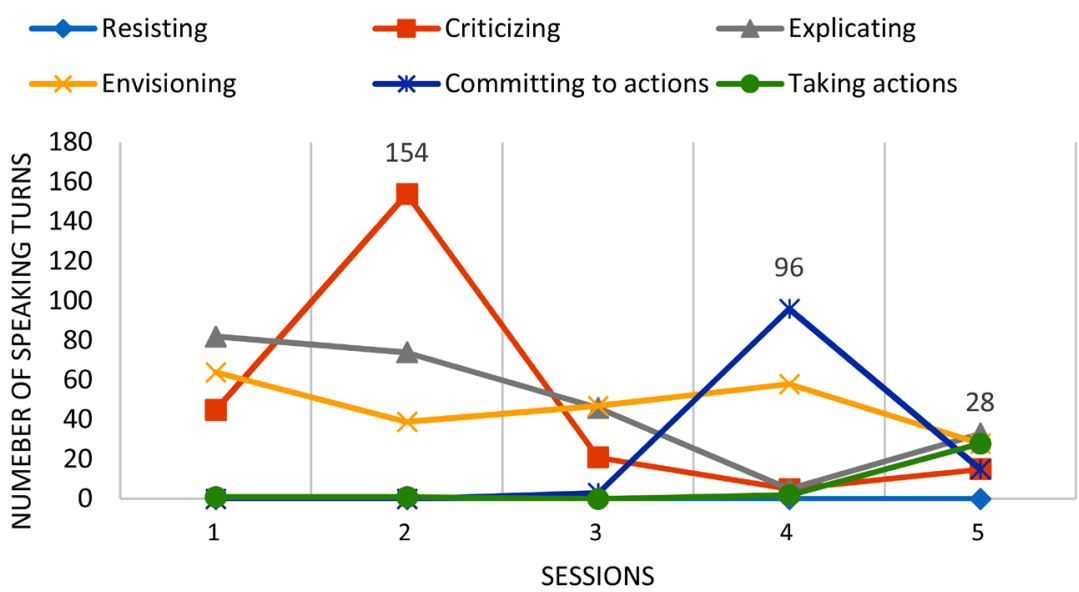

Figure 3. The evolution of the types of expressions of transformative agency over the course of the workshop sessions.

the second workshop revealed the challenges and problems in the development of the neighbourhood's past, present and future. The presentation of the mirror data in the second workshop launched multiple opinions and perspectives, achieving the highest number (268) of agentive speaking turns. It may be said that the matching mirror data launched the issues which need improving and exhibit tensions. Committing to actions reached its highest point (96) in the fourth workshop, the purpose and content of which was to inspire the participants to plan their own experimental implementations together with their group. This indicates that when the participants are able to plan their own activities and cultivate their own ideas, they also engage with the implementation of the activity.

The agency type of explicating new possibilities and potentials in the activity was visible at a high and regular level in the beginning but dropped quite clearly during the fourth workshop. This may be due to the fourth workshops' programme, which was quite instruction-oriented, with the preparation of the experimental implementations through guided group activities. The agency type of envisioning the new patterns or models was regular during the whole workshop process, being represented strongly as early as the first workshop. We may interpret this finding as workshop sessions being strong in nurturing new ideas along the process. The workshops managed to keep the participants active and trusting in the constructive and positive collaboration regarding the neighbourhood in the future. The type of expression of taking actions had the lowest score, reached its peak (28) in the fifth workshop. The fifth workshop was strong in allowing all the agency types, except resisting, to emerge, and enabled action taking.

To sum up, criticizing (240), explicating (240) and envisioning (236) were the most frequent expressions of the agency types. It is typical that criticizing and explicating lead to envisioning new patterns or models for the activity by recon- 
structing its object, the original motive and purpose of the activity. The workshops were strong in the "middle ground", enabling participants to criticize, explicate new possibilities and envision new patterns and models during the course of the workshops (see Haapasaari et al., 2016). A high number of the expressions of criticizing, explicating and envisioning may indicate the need for a common discussion to present and acquire information, define requirements based on the needs in the neighbourhood, and affect other people. We may interpret this as the workshop process enabling participants to reveal their thoughts, and by sharing their ideas thus laying the ground for future collaboration.

However, the two peaks in curves, criticizing and committing to actions, make the pattern of the evolution of the agency types unequal. This may indicate that the five-session period was too short and interventionist- and instruction-oriented to keep up a steady rhythm, and thus channelled the evolution of the agency quite strongly. The large number of participants called for controlling the sessions with instructions, which decreased the open talk and thus prevented free and steady evolution of the expressions in some sessions. The second workshop invoked a high number of manifestations concerning the central issues in urban development, including criticism. This indicates that the historical analysis of the development of the neighbourhood was critical to the change process.

\subsection{Discussion Topics Connected to the Types of Expressions of Transformative Agency}

The identification of the topics of the data yielded 282 topical episodes in total. This helped to keep the data coherent during the analysis and avoided separating it into scattered parts. Some episodes (8) included more than one topic and they were coded in all those topics, yielding 290 topical episodes altogether. The types of expressions of transformative agency triggering the topics based on the activity system model were perceived in each topical episode. The numbers of each topic expressed by each type of expression of transformative agency are shown in Table 4.

Table 4. The topics of the types of expressions transformative agency in workshops.

\begin{tabular}{cccccccc}
\hline Topic & Resisting & Criticizing & Explicating & Envisioning & $\begin{array}{c}\text { Committing } \\
\text { to actions }\end{array}$ & $\begin{array}{c}\text { Taking } \\
\text { actions }\end{array}$ & Total \\
\hline Subject & 0 & 12 & 14 & 8 & 1 & 0 & 35 \\
Object & 0 & 47 & 88 & 66 & 15 & 7 & 223 \\
Tools & 0 & 43 & 58 & 91 & 42 & 15 & 249 \\
Rules & 0 & 58 & 20 & 7 & 2 & 0 & 87 \\
Community & 0 & 10 & 11 & 25 & 4 & 0 & 50 \\
Division of labour & 0 & 70 & 49 & 39 & 48 & 10 & 216 \\
Participation & 0 & 0 & 0 & 0 & 2 & 0 & 2 \\
Total & 0 & 240 & 240 & 236 & 114 & 32 & 862 \\
\hline
\end{tabular}


The tools (249) in the activity system were the most frequently mentioned topic in the workshops. The object of the activity system (223) and the division of labour (216) were the second- and the third-most frequent and almost evenly manifested topics in the episodes. The topics of the rules (87), community (50) and the subject (35) of the activity system were clearly expressed less than the others were. The least expressed topic was the extra topic of participation (2).

The topic of tools was strong in the types of expressions of criticizing (43), explicating (58), envisioning (91) and committing to actions (42) and this may indicate that the participants need new tools for collaboration and participation. The tools may be a pain point in the urban development, and the actors may not be ready to proceed to solving the challenge. This may relate to the feeling that the developmental tools are almost missing, that they need reconceptualization, or that the actors do not simply recognize them. On the other hand, the professionals and specialists from various cross-sectorial fields conduct usually the official bureaucratic development work at a remove from the residents. Municipalities are quite unapproachable. The application of the method of Change Laboratory as a new tool in urban development provided strong motivation for the participants to innovate new tools for their neighbourhood development. That a large number of the envisionings concerned future-oriented suggestions for tools may indicate that new tools and means of collaboration is a timely topic.

The topic of division of labour was strong in the type of expressions of criticizing (70), explicating (49), envisioning (39) and committing to actions (48). It had its highest peak in criticizing. This may reflect that the responsibilities and roles of the actors in the development work are unclear. It may also associate with residents' need to establish of their own community through collective activities. Since the tools and division of labour demonstrate high frequency in the same types of expressions, they may be tightly connected to each other. This may indicate that the community of urban actors is fragmented and they lack common tools.

The topic of the object of the activity had its highest peak when participants explicated new possibilities or potentials in the activity (88), but it was also criticized (47) and envisioned (66). This shows that participants took an active role to modify the object in the development work. It is quite typical that the object is explicated often, since the aim of the method of Change Laboratory is to elaborate the joint object of the activity from several perspectives. This indicates that the participants started to redefine the object of activity, and perhaps that participants thought of new possibilities and potentials focused on the development of the neighbourhood.

At this point, it is necessary to note an interesting peak of criticizing, which was connected to rules (58). This may indicate that the rules are connected to the tools, object and division of labour, which were the most frequently mentioned elements. It is quite understandable that the common rules are connected to the division of labour. The expressions are, however, difficult to discern be- 
cause the elements of the activity system were so intertwined in the data. An artefact that is commonly used as a tool, like governance practices, can also be considered as a rule depending on the perspective. This confuses the analysis of the elements of the activity system (see Engeström, 1990).

The less mentioned topics of agentive expressions were focused on the topics of community (50) and subject (35) of the activity. Interestingly, the community of the activity reaches its highest peak in envisioning. Maybe the workshops provided an opportunity for future-oriented envisioning, building and strengthening the coherence of residents' emerging community. Besides, the existence of a community calls for a collective way of working and appropriate division of work (cf. Leont'ev, 1978). The subject of activity was not raised so much, which may indicate that the participants did not consider anyone as a leading actor: after all, urban development is many-sided. Since the urban plans range widely it is difficult to perceive what concerns whom.

The topic of participation was mentioned twice. Some of the residents wanted to express their interest in the experimental implementation. They wanted to be present or available in the implementation, without exactly committing to do anything. We can interpret this as them wanting to belong to the group and promote the process but not clearly understanding their roles and responsibilities yet. The responsibilities in the developmental issues were obscure to the residents. They were not ready to take action on them.

To summarize, criticizing appears most frequently in the elements of division of labour (70), rules (58), object of activity (47) and tools (43) of the activity system. The agency type of explicating new possibilities or potentials in the activity appeared mostly in the object of activity (88), tools (58) and division of labour (49) of the activity system. The agency type of envisioning new patterns or models in the activity reached its highest peak in tools (91), which was clearly more than the others. The object of activity (66) and division of labour (39) were the second- and third-most envisioned elements. Agency type of committing to actions concerned mostly the division of labour (48) and tools (42). The agency type of taking actions was a relatively steady curve focusing mostly on tools (15), and it did not trigger the topics of subject, rules or community at all.

The highest frequencies of the type of expressions of transformative agency concerning the elements of the activity system were observed in the criticism of division of labour (70), explication of the object of activity (88), envisioning of the tools (91) and committing to actions in the division of labour (48). The topics of tools, object of activity and division of labour were expressed most frequently, and these topics are strongly connected to each other. This indicates that there are challenges in targeting the object in urban development as well as in finding suitable tools and dividing up the work. This is understandable since the challenges and problems in the cities are complex and connected to economic, social and physical levels (see Baynes, 2009). There are many regulations and limitations that require attention in the municipalities, and development is many- 
sided, long-lasting and concerns many. The application of the method of Change Laboratory enabled the triggering of the topics, guided by the elements of the activity system. The topics were manifested by almost all the types of expressions of transformative agency, except resisting. It can be said that the workshop process consisted of talkative and active gatherings where the participants concentrated to plan their experimental practice-based implementations and create relations for their community. Through their experimental implementations, they created activities and tools for developing their neighbourhood. The emergence of the topics related to each type of expressions of transformative agency is shown in the curves in Figure 4.

\section{Discussion and Conclusion}

The study indicates a theoretical illustration of the emergence of residents' and civil servants' transformative agency by turning it into operational conceptual tools for analysing the empirical data. The method of Change Laboratory provided a structure for utilizing the complex urban situation to start the collective work (the first stimulus), and to facilitate the unveiling process of the contradictions with the help of an explicit tool, the model of activity system (the second stimulus). The analysis enabled to identify the topics of the discussions and the emergence of the types of expressions of transformative agency across the workshops in dialectical movement through time and revealed the development of transformative agency and collaboration efforts between civil society and civil servants.

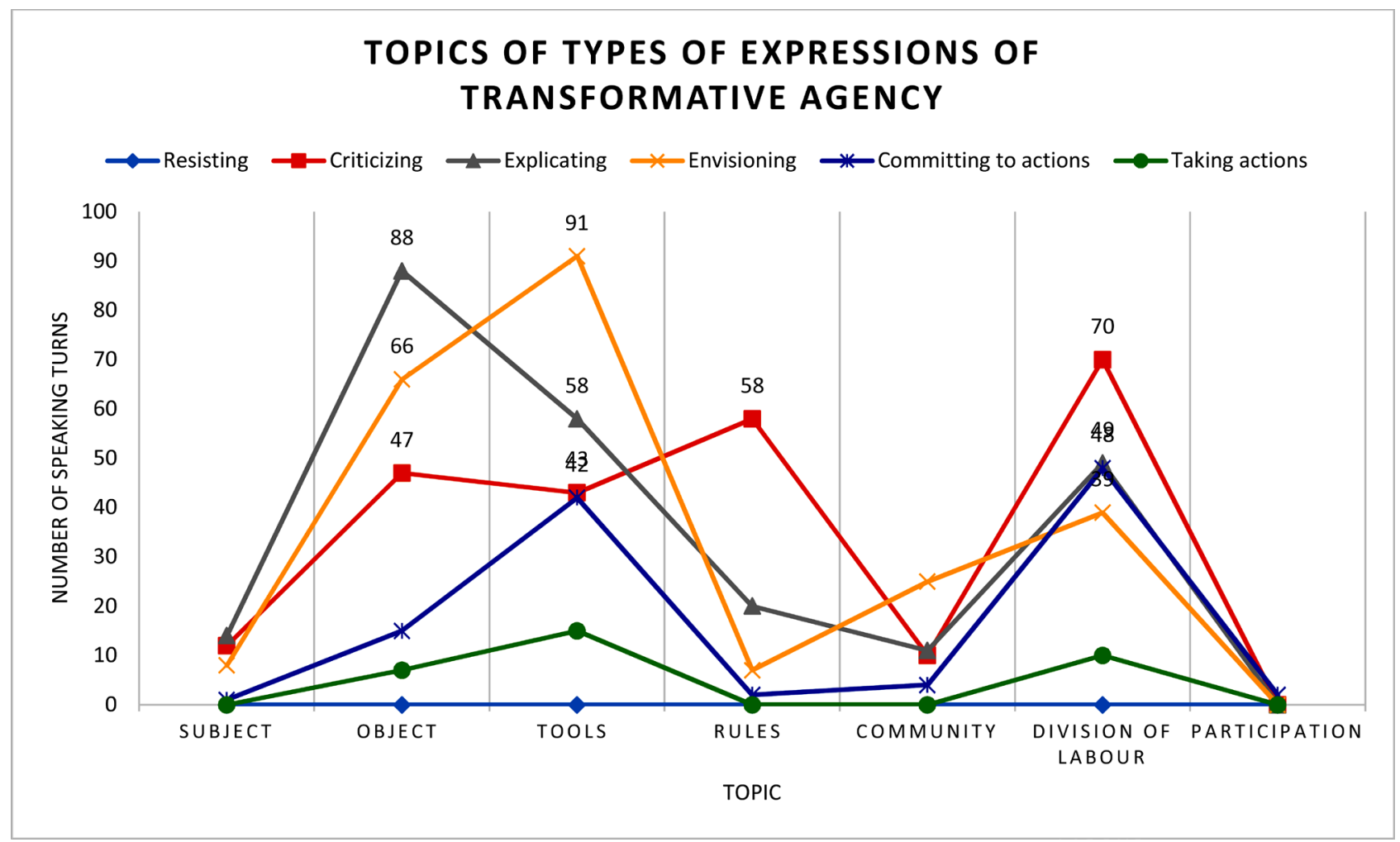

Figure 4. The evolution of the topics of types of expressions of transformative agency in workshops. 
In the neighbourhood, the contradiction lies between the residents' need to participate in decision-making processes and the public sector's need to enhance the collaboration between administration and civil society. The topics of tools, object of activity, and division of labour were manifested with a high frequency. There is a need for a common discussion, new tools and means of collaboration, and the clarification of the roles of urban actors and the coordination of activities in the city. Residents were able to plan and implement their own activities. They could build their transformative agency through organizing practical local activities such as workshops, a food festival, and public events, but they need collaboration with civil servants. However, the collective way of working requires rules in urban development. Thus, it is possible for the residents to develop their transformative agency together with civil servants and participate in decision-making processes.

The emergence of transformative agency and collective learning is time-consuming and complicated between multi-sectorial administration and civil society. Further research is needed to strengthen the long-term development of transformative agency and collaboration in urban development.

\section{Acknowledgements}

I warmly thank the fellow researchers Soile Juujärvi, Kaija Pesso and Ossi Salin at Laurea University of Applied Sciences, Espoo, Finland, and the interventionist Minna Hägg from Migga coaching and development services, Helsinki, Finland, for their help in conducting the application of Change Laboratory process during the research project Caring and Sharing Networks. I would like to express my gratitude to researcher Hannele Kerosuo at Tampere University for her valuable comments on the manuscript. I also thank all participants in this study. The study was funded by the Housing Finance and Development Centre of Finland and the Ministry of Environment through the Development Programme for Residential Areas (2013-2015). The research was conducted in accordance with research protocol concerning human participants. Written informed consent was obtained from all participants. The author declares that there is no conflict of interest.

\section{Conflicts of Interest}

The author declares no conflicts of interest regarding the publication of this paper.

\section{References}

Arnstein, S. R. (1969). A Ladder of Citizen Participation. Journal of the American Institute of Planners, 35, 216-224. https://doi.org/10.1080/01944366908977225

Baynes, T. (2009). Complexity in Urban Development and Management. Historical Overview and Opportunities. Journal of Industrial Ecology, 13, 214-227.

https://doi.org/10.1111/j.1530-9290.2009.00123.x 
City of Espoo. (2013). Espoolaisten Hyvinvoinnin Tila 2013. [Residents' Welfare in Espoo 2013]. (Last Checked 9 July 2021)

http://www.espoo.fi/download/noname/\%7B9E12E7E2-7102-41BB-AFDA-7F58676952 $\underline{\mathrm{D} 5 \% 7 \mathrm{D} / 40374}$

Engeström, Y. (1990). Learning, Working and Imagining. Twelve Studies in Activity Theory. Orienta-Konsultit Oy.

Engeström, Y. (2007). Putting Activity Theory to Work: The Change Laboratory as an Application of Double Stimulation. In H. Daniels, M. Cole, \& J. V. Wertsch (Eds.), The Cambridge Company to Vygotsky (pp. 363-382). Cambridge University Press. https://doi.org/10.1017/CCOL0521831040.015

Engeström, Y. (2009). The Future of Activity Theory: A Rough Draft. In A. Sannino, H. Daniels, \& K. Gutierrez (Eds.), Learning and Expanding with Activity Theory (pp. 303 338). Cambridge University Press. https://doi.org/10.1017/CBO9780511809989.020

Engeström, Y. (2011). From Design Experiments to Formative Interventions. Theory and Psychology, 21, 598-628. https://doi.org/10.1177\%2F0959354311419252

Engeström, Y. (2015). Learning by Expanding. An Activity-Theoretical Approach to Developmental Research. Cambridge University Press. https://doi.org/10.1017/CBO9781139814744

Engeström, Y. (2016). Studies in Expansive Learning: Learning What Is Not yet There. Cambridge University Press. https://doi.org/10.1017/CBO9781316225363

Engeström, Y., \& Sannino A. (2010). Studies on Expansive Learning. Foundations, Findings and Future Challenges. Educational Research Review, 5, 1-24.

https://doi.org/10.1016/j.edurev.2009.12.002

Engeström, Y., \& Sannino, A. (2013). La Volition et l'Agentivite Transformatrice: Perspective Theorique de l'Activite [Volition and Transformative Agency: An Activity-Theoretical Perspective]. Revue Internationale du CRIRES: Innover dans la Tradition de Vygotsky, 1, 4-19. https://doi.org/10.51657/ric.vlil.41017 https://revues.ulaval.ca/ojs/index.php/RIC/article/view/41017

Engeström, Y., Sannino, A., \& Virkkunen, J. (2014). On the Methodological Demands of Formative Interventions. Mind, Culture, and Activity, 21, 118-128. https://doi.org/10.1080/10749039.2014.891868

Engeström, Y., Virkkunen, J., Helle, M., Pihlaja, J., \& Poikela, R. (1996). Change Laboratory as a Tool for Transforming Work. Lifelong Learning in Europe, 1, 10-17.

Forester, J. (1982). Planning in the Face of Power. Journal of the American Planning Association, 48, 67-80. https://doi.org/10.1080/01944368208976167

Haapasaari, A., Engeström, Y., \& Kerosuo, H. (2016). The Emergence of Learner's Transformative Agency in a Change Laboratory Intervention. Journal of Education and Work, 29, 232-262. https://doi.org/10.1080/13639080.2014.900168

Healey, P. (1992). Planning through Debate: The Communicative Turn in Planning Theory. Town Planning Review, 63, 143.

https://doi.org/10.3828/tpr.63.2.422x602303814821

Hirvonen, J. (2011). Suvela Tilastoissa ja Asukkaiden Kokemana. [Suvela in Statistics and Residents' Experiences]. Aalto University Publications TIEDE + TEKNOLOGIA 17/2011. Aalto University. (Last Checked 9 July 2021) https://aaltodoc.aalto.fi/bitstream/handle/123456789/5122/isbn9789526042510.pdf?seq uence $=1$ \&isAllowed $=y$

Karaminejad, Z. (2021). The Relationship between Pre-Collaboration and Community Resi- 
liency: A Case of Housing Renewal Project in New Zealand. Current Urban Studies, 9, 279-298. https://doi.org/10.4236/cus.2021.92018

Lehtinen, T. (2016). Espoo Alueittain 2015: Analyysit Teemoittain ja Suuralueittain. [Espoo in Districts 2015]. Tietoisku 7/2016. City of Espoo. (Last Checked 9 July 2021) http://www.espoo.fi/download/noname/\%7B498E81B4-92B3-4A69-808A-DDDD33470 E7D $\% 7 \mathrm{D} / 73080$

Leont'ev, A. N. (1978). Activity, Consciousness, Personality. Prentice Hall.

Local Government Act (410/2015). (Last Checked 9 July 2021) https://www.finlex.fi/fi/laki/kaannokset/2015/en20150410.pdf/

Lund, V., \& Juujärvi, S. (2018). Residents' Agency Makes a Difference in Volunteering in an Urban Neighbourhood. VOLUNTAS: International Journal of Voluntary and Nonprofit Organization, 29, 756-769. https://doi.org/10.1007/s11266-018-9955-4

Lund, V., \& Kerosuo, H. (2019). The Reciprocal Development of the Object of Common Space and the Emergence of the Collective Agency in Residents' Workshops. Learning, Culture and Social Interaction, 22, Article ID: 100327.

https://doi.org/10.1016/j.lcsi.2019.100327

Sandercock, L. (1998). Towards Cosmopolis: Planning for Multicultural Cities. J. Wiley.

Sannino, A. (2008). From Talk to Action: Experiencing Interlocuting in Developmental Interventions. Mind, Culture, and Activity, 15, 234-257.

https://doi.org/10.1080/10749030802186769

Sannino, A. (2015). The Principle of Double Stimulation: A Path to Volitional Action. Learning, Culture, and Social Interaction, 6, 1-15. https://doi.org/10.1016/j.lcsi.2015.01.001

Steen, T., Brandsen, T., \& Verschuere, B. (2018). The Dark Side of Co-Creation and CoProduction: Seven Evils. In T. Brandsen, T. Steen and B. Verschuere (Eds.), Co-Production and Co-Creation (pp. 284-293). Routledge. https://doi.org/10.4324/9781315204956-45

Virkkunen, J. (2006). Dilemmas in Building Shared Transformative Agency. Activites Revue Electornique, 3, 43-66. https://doi.org/10.4000/activites.1850

Virkkunen, J., \& Newnham, D. (2013). The Change Laboratory. Sense Publishers. https://doi.org/10.1007/978-94-6209-326-3

Vygotsky, L. (1978). Mind in Society. The Development of Higher Psychological Processes. Harvard University Press.

Vänninen, I., Pereira-Querol, M., \& Engeström, Y. (2015). Generating Transformative Agency among Horticultural Producers: An Activity-Theoretical Approach to Transforming Integrated Pest Management. Agricultural Systems, 139, 38-49.

https://doi.org/10.1016/j.agsy.2015.06.003 